\title{
Axillary Surgery in Breast Cancer Patients Treated with Breast-Conserving Surgery at German Breast Cancer Centers Within the Last 14 Years - Comparison of a University Center and a Community Hospital
}

\author{
Operatives Axillastaging bei brusterhaltender Therapie \\ über die letzten 14 Jahre an zertifizierten Brustzentren - \\ Vergleich zwischen einem Universitätszentrum und \\ einem städtischen Haus
}

\section{(ㄷ) (1) (옹}

Authors

Amelie de Gregorio ${ }^{1}$, Peter Widschwendter ${ }^{1}$, Susanne Albrecht ${ }^{1}$, Nikolaus de Gregorio ${ }^{1}$, Thomas W. P. FriedI ${ }^{1}$, Jens Huober ${ }^{1}$, Wolfgang Janni ${ }^{1}$, Florian K. Ebner ${ }^{2}$

Affiliations

1 Department of Gynecology and Obstetrics, University Hospital Ulm, Ulm, Germany

2 Department of Gynecology and Obstetrics, Helios Hospital Amper, Dachau, Germany

Key words

breast cancer, national guidelines, treatment changes, sentinel node biopsy, axillary lymph node dissection

Schlüsselwörter

Brustkrebs, nationale Richtlinien, Änderungen in der Behandlung, Wächter-Lymphknotenbiopsie, Axilladissektion

$\begin{array}{ll}\text { received } & 3.9 .2018 \\ \text { revised } & 21.9 .2018 \\ \text { accepted } & 25.9 .2018\end{array}$

Bibliography

DOI https://doi.org/10.1055/a-0750-1880

Geburtsh Frauenheilk 2018; 78: 1138-1145 @ Georg Thieme Verlag KG Stuttgart · New York | ISSN 0016-5751

Correspondence

Dr. Amelie de Gregorio

University of Ulm, Department of Obstetrics and Gynecology Prittwitzstraße 43, 89075 Ulm, Germany

Amelie.degregorio@uniklinik-ulm.de

\section{ABSTRACT}

Background Guideline recommendations for axillary surgical approach in breast cancer (BC) treatment changed over the last decade.

Methods Data from all invasive BC patients $(n=5344)$ treated with breast conserving surgery (BCS) at the breast cancer centers of the University Hospital Ulm (U-BCC) and the community hospital Dachau (D-BCC) were included into a retrospective analysis for assessing information on axillary surgery between 2003 and 2016 based on the documented cancer registry data.

Results The average annual rate of sentinel node biopsy (SNB) was $85.5 \%$ and $87.2 \%$ in Ulm and Dachau, respectively. SNB was performed more precisely at the U-BCC with a median of 2.4 resected lymph nodes (LN) compared to a median of 3.2 resected LN in Dachau. Median number of resected LN for axillary lymph node dissection (ALNE) showed a statistically significant reduction over time in Ulm $\left(r_{s}=-0.82\right.$; $p<0.001)$ and Dachau $\left(r_{s}=-0.76 ; p=0.002\right)$. The rate of secondary ALNE (after SNB; $2^{\circ}$ ALNE) decreased significantly in U-BCC $\left(r_{s}=-0.76 ; p=0.002\right)$ while it remained stable in D-BCC. The influential publication of the Z0011 study in 2010 resulted in a significant reduction of secondary ALNE (24.1\% preZ0011 and 14.4\% postZ0011; $\mathrm{p}<0.001$ ) in Ulm.

Conclusion Changes in axillary surgery over time can be seen in the annual statistics of the reviewed BCCs. With BCS, mostly SNB was performed and numbers of removed LN in ALNE have decreased. In the U-BCC, the rate of $2^{\circ}$ ALNE dropped after the publication of the Z0011 data. The fact that no such decrease for $2^{\circ}$ ALNE was found in D-BCC suggests that university hospitals implement new data and research results into clinical routine earlier than peripheral community hospitals. 


\section{ZUSAMMENFASSUNG}

Hintergrund In den letzten 10 Jahren haben sich die Empfehlungen zum operativen Vorgehen in der Axilla bei Mammakarzinompatientinnen gewandelt.

Methoden Die Daten von insgesamt 5344 Patientinnen mit invasivem Brustkrebs, die sich entweder im Brustzentrum des Universitätsklinikums Ulm (U-BCC) oder im Helios Amper-Klinikum Dachau (D-BCC) einer brusterhaltenden Therapie (BET) unterzogen, wurden basierend auf den dokumentierten anonymisierten Tumorregisterdaten retrospektiv zwischen 2003 und 2016 analysiert, um neue Trends im chirurgischen Vorgehen bei Axillainterventionen zu identifizieren.

Ergebnisse Im Durchschnitt wurden pro Jahr bei 85,5\% der in Ulm und $87,2 \%$ der in Dachau mittels BET behandelten Patientinnen Wächterlymphknoten-Biopsien (SNB) durchgeführt. Dabei betrug die mittlere Anzahl an entfernten Lymphknoten (LN) pro SNB in Ulm 2,4 verglichen zu 3,2 LN in Dachau. Die mediane Anzahl an entfernten LN pro Axilladissektion reduzierte sich im Verlauf des Beobachtungszeit- raums sowohl in Ulm $\left(r_{s}=-0,82 ; p<0,001\right)$ als auch in Dachau $\left(r_{s}=-0,76 ; p=0,002\right)$. Im Laufe der Jahre nahm zudem die Rate an sekundären Axilladissektionen (nach SNB, $2^{\circ}$ ALNE) im U-BCC signifikant ab $\left(r_{s}=-0,76 ; p=0,002\right)$, wohingegen sie in D-BCC stabil blieb. Mit Veröffentlichung der Ergebnisse der Z0011-Studie im Jahr 2010 kam es in Ulm zu einem statistisch signifikanten Rückgang an sekundären ALNE (24,1\% vor Z0011 und 14,4\% nach Z0011; p<0,001).

Schlussfolgerung Die jährlichen Statistiken der untersuchten Brustzentren zeigen deutliche Trends im operativen Axillastaging bei Mammakarzinompatientinnen mit BET über die letzten Jahre. Bei der Mehrheit der Patientinnen wurde eine BET mit SNB durchgeführt. Während in beiden Zentren die Zahl der durchschnittlich pro ALNE entnommenen LN über die Jahre signifikant abnahm, ging mit der Publikation der Z0011-Studie auch die Rate an sekundären ALNEs selbst in Ulm zurück. Nachdem ein derartiger Trend für das D-BCC nicht beobachtete werden konnte, kann vermutet werden, dass neue Daten schneller Einzug in die klinische Routine von universitären Brustzentren erhalten.

\section{Introduction}

Treatment recommendations based on national and international guidelines for surgical therapy of newly diagnosed invasive breast cancer have continuously changed over the last decades. In accordance with the widespread trend in breast cancer surgery of reduced surgical radicalism to avoid excessive morbidity, axillary surgery in breast cancer was redefined. The most obvious change is the implementation of the sentinel node concept - now considered as standard of care. It has dramatically reduced the morbidity of axillary surgery in patients with nodal-negative breast cancer without compromising the oncological safety or diagnostic accuracy. Women with clinical node-negative breast cancer can be safely treated with sentinel node biopsy (SNB) instead of complete resection of axillary lymph nodes (LN) [1-5]. Nevertheless, presence of at least one positive sentinel lymph node resulted in a general recommendation for subsequent axillary lymph node dissection (ALNE). In 2010, the publication of the ACOSOG Z0011 trial challenged this approach. According to the results of the Z0011 study, patients with breast conserving surgery (BCS), T1/2 tumors and one or two positive sentinel lymph node(s) do not need subsequent ALNE when whole breast radiation follows surgery [6, 7]. Following the publication of the Z0011 study, ALNE in BCS patients became restricted to defined situations.

However, both the results of the Z0011 study and their clinical implications were controversially discussed, and some methodical weaknesses warrant a cautious interpretation. Preterm ending of study recruitment resulted in fewer participants and events than planned and thereby insufficient statistical power. Furthermore, there was also some bias as a proportion of patients underwent additional regional nodal irradiation.

Parallel to these developments, axillary surgery itself changed. Surgeons removed less lymph nodes (LN) in ALNE for reducing patients morbidity like lymphedema and paresthesia [8], especially as the number of removed lymph nodes did not improve the survival [9]. Also breast surgery adapted new definitions of adequate resection margins into the clinical routine. The minimum tumorfree margin had been postulated with one $\mathrm{mm}[10,11]$ and was further reduced to "no ink on tumor" as a sufficient tumor free margin. In 2014, the use of no ink on tumor was included in the consensus guidelines of the Society of Surgical Oncology and American Society for Radiation Oncology for stage I/II tumors with BCS and whole-breast irradiation [12]. With only tumor-free margins, the volume of resected tissue samples was reduced. This resulted in a higher overall rate of breast conserving surgeries and also decreased the number of secondary resections to gain a sufficient tumor free margin [13]. The German S3-national guideline for treatment of breast cancer $(\mathrm{GL})$ requested a resection margin of at least one $\mathrm{mm}$ in patients with BCS from their first version in 2004 until the third version of 2012. In the third version of 2012 , the results of the Z0011 study were mentioned for the first time. Patients meeting the Z0011 inclusion criteria could optionally being treated according to the Z0011 study protocol without an ALNE. Nevertheless, standard treatment in case of a positive SNB for patients with BCS was ALNE with a minimum of 10 removed LNs. In 2017, the GL demands “no ink on tumor" as adequate margins and does not include a definition of the amount of lymph nodes required for sufficient ALNE. Following the consensus of the Society of Surgical Oncology, omission of secondary ALNE in patients meeting the Z0011 criteria is also recommended by the GL [14-16].

Ultimately, guidelines changes and new treatment recommendations need time for implementation into clinical routine [17]. This might happen more promptly in University hospitals than non-university departments. There is an established national network for guideline development, implementation and evaluation in Germany [18], and annual statistics for breast cancer surgery have to be submitted to the national cancer centers. Based on 
these annual status reports, anonymized information on axillary surgery were available from the certified breast centers in UIm and Dachau. Based on the analysis of these data over a time-period of 14 years, we assessed the implementation of new clinical data and guideline changes in surgical treatment of breast cancer patients with BCS. Potential differences between surgical parameters and therapy approaches in a university hospital center and a peripheral community hospital were analyzed by comparing the findings between both BCC. Thereby, the aim of the study is to identify possible delays in the implementation of guideline changes depending on the hospital setting.

\section{Methods}

Annual retrospective reports with anonymized data from patients treated for BC are statutorily forwarded to the German national cancer centers and were therefore digitally available. The data include information on clinical tumor- and patient characteristics as well as surgical details, and the annual reports are available for every certified breast cancer center. All reports from the certified breast cancer centers of the University Hospital Ulm and the community hospital Dachau were retrospectively analyzed for the time-period from 2003 until 2016.

\section{Patients' characteristics}

All data was extracted from the statutorily requested anonymized annual reports. Data analysis was restricted to patients with early invasive BC treated with BCS. Patients with neoadjuvant chemotherapy, carcinoma in situ or mastectomy were excluded. Anonymized data from the defined patients' collective were assessed for type of axillary surgery with primary SNB, primary ALNE (preoperatively planned ALNE) or secondary ALNE after positive SNB ( $2^{\circ}$ ALNE). The number of removed $L N$ for SNB and ALNE was documented in terms of median values of resected lymph nodes per year. All procedures performed in this study were in accordance with the ethical standards of the institutional committee and did not require a separate ethical approval.

\section{Statistical analysis}

Between January 1st of 2003 and December 31st 2016, 5438 patients were treated with BCS for newly diagnosed, invasive breast cancer without prior neoadjuvant chemotherapy at the BCC of the University hospital Ulm $(n=2911)$ and the hospital Dachau $(n=2527)$. For 37 and 57 patients in Ulm and Dachau, respectively, the type of surgery was not specified, resulting in a total of 5344 patients (2874 patients at the BCC Ulm and 2470 patients at the BCC Dachau) that could be included for the subsequent analyses.

Categorical variables were described with absolute and relative frequencies and descriptive statistics of continuous variables comprised medians and ranges. Associations between categorical variables were analyzed with $X^{2}$ tests. Correlation tests were performed using Spearman's rank correlation coefficient $r_{s}$. Statistical analyses were performed using the SPSS statistical software package, version 24 (IBM, New York, NY, USA). All statistical tests were two-sided and $\mathrm{p}$-values lower than 0.05 were considered significant.

\section{Results}

\section{Type of axillary surgery}

The rate of SNB increased from 59.9\% in 2003 up to $79.4 \%$ in 2016 (94.6\% in 2015) in Ulm (total number of SNB $=2458$ ) and from $49.0 \%$ in 2003 up to $97.1 \%$ in 2016 in Dachau (total number of SNB $=2154$ ). Overall, SNB was performed in $85.5 \%$ of all patients treated with $\mathrm{BCS}$ for invasive breast cancer in the university $\mathrm{BCC}$ (U-BCC) and in $87.2 \%$ in the municipal BCC (D-BCC). A statistically significant increase in the rate of performed SNBs between 2003 and 2016 was found for Dachau $\left(r_{s}=0.89 ; p<0.001\right)$ but not for Ulm $\left(r_{s}=0.33 ; p=0.25\right)$.

Primary ALNE was performed on average in $11.6 \%$ (U-BCC) respectively $9.1 \%$ (D-BCC) of patients with BCS during the last 14 years. The rate of primary ALNE showed a peak in 2003 with $39.5 \%$ in Ulm and $40.8 \%$ in Dachau with a continuous decrease since then ( $\triangleright$ Fig. 1 a and b). In 2016, primary ALNE was only performed in $6.0 \%$ respectively no patient in Dachau. For both BCCs a statically significant reduction in the rate of performed primary ALNE over time was found (U-BCC: $r_{s}=-0.73 ; p=0.003$, D-BCC: $\left.r_{s}=-0.90 ; p<0.001\right)$. No lymph-node intervention was performed in $2.9 \%$ (U-CC) and 3.7\% (D-BCC) of patients.

Over the reviewed time-period, the rate of $2^{\circ}$ ALNE (out of all SNBs) was $16.6 \%$ in Ulm and $14.3 \%$ in Dachau. Rate of conversion from SNB to ALNE was in $200329.1 \%$ (U-BCC) respectively $15.8 \%$ (D-BCC) and $7.5 \%(U-B C C)$ respectively $17.9 \%$ (D-BCC) in the year 2016 ( $\triangleright$ Fig. 1 a and b). In Ulm, the rate of $2^{\circ}$ ALNE decreased significantly over the years $\left(r_{s}=-0.76 ; p=0.002\right)$, while no such decrease was observed in Dachau $\left(r_{s}=-0.04 ; p=0.89\right)$.

Comparing the conversion rate of SNB to secondary ALNE in the years before (2003-2009) the ACOSOG Z0011 publication in 2010 and the years afterwards (2011-2016), significant changes were observed at the university center. Secondary ALNE in BCS treated patients at the U-BCC was performed prior to study publication in $24.1 \%$ of the patients (preZ0011: $n=284$ out of 1177 SNBs) and afterwards in $14.4 \%$ of the patients (postZ0011: $n=155$ out of 1076 SNBs), resulting in a statistically significant reduction of the rate of secondary ALNE after the publication of Z0011 data $\left(X^{2}=33.9 ; p<0.001\right)$. In contrast, in Dachau no difference with regard to the rate of performed $2^{\circ}$ ALNE before or after the publication of the Z0011 study in 2010 could be found (preZ0011: 16.8\%; $n=222$ out of 1321 SNBs; post-Z0011: 16.8\%; $\mathrm{n}=102$ out of 608 SNBs; $\left.\mathrm{x}^{2}=0.0 ; \mathrm{p}=0.99\right)$ ( $\triangleright$ Fig. $2 \mathbf{a}$ and $\mathbf{b}$ ).

\section{Number of removed lymph nodes}

The median number of LN removed for SNB was $2.4 \mathrm{LNs}$ in the $\mathrm{U}-\mathrm{BCC}$ and $3.2 \mathrm{LNs}$ in the D-BCC. The median number of resected LN for ALNE was 15.7 LNs in Ulm versus 11.5 in Dachau. As shown in $>$ Fig. 3 , the number of resected LN for ALNE decreased during the observational period. In Ulm, the highest median number of removed axillary LNs was $20.3 \mathrm{LNs}$ in 2005 with a minimum of $6 \mathrm{LNs}$ in 2015. For D-BCC, the maximal annual median number of dissected axillary LNs was 16.5 in 2003 with a minimum of 10.0 LNs in 2015 (see - Fig. 3). Annual median numbers of resected LN for ALNE showed a statistically significant decrease over time both in Ulm $\left(r_{s}=-0.82 ; p<0.001\right)$ and Dachau $\left(r_{s}=-0.76 ; p=0.002\right)$. 


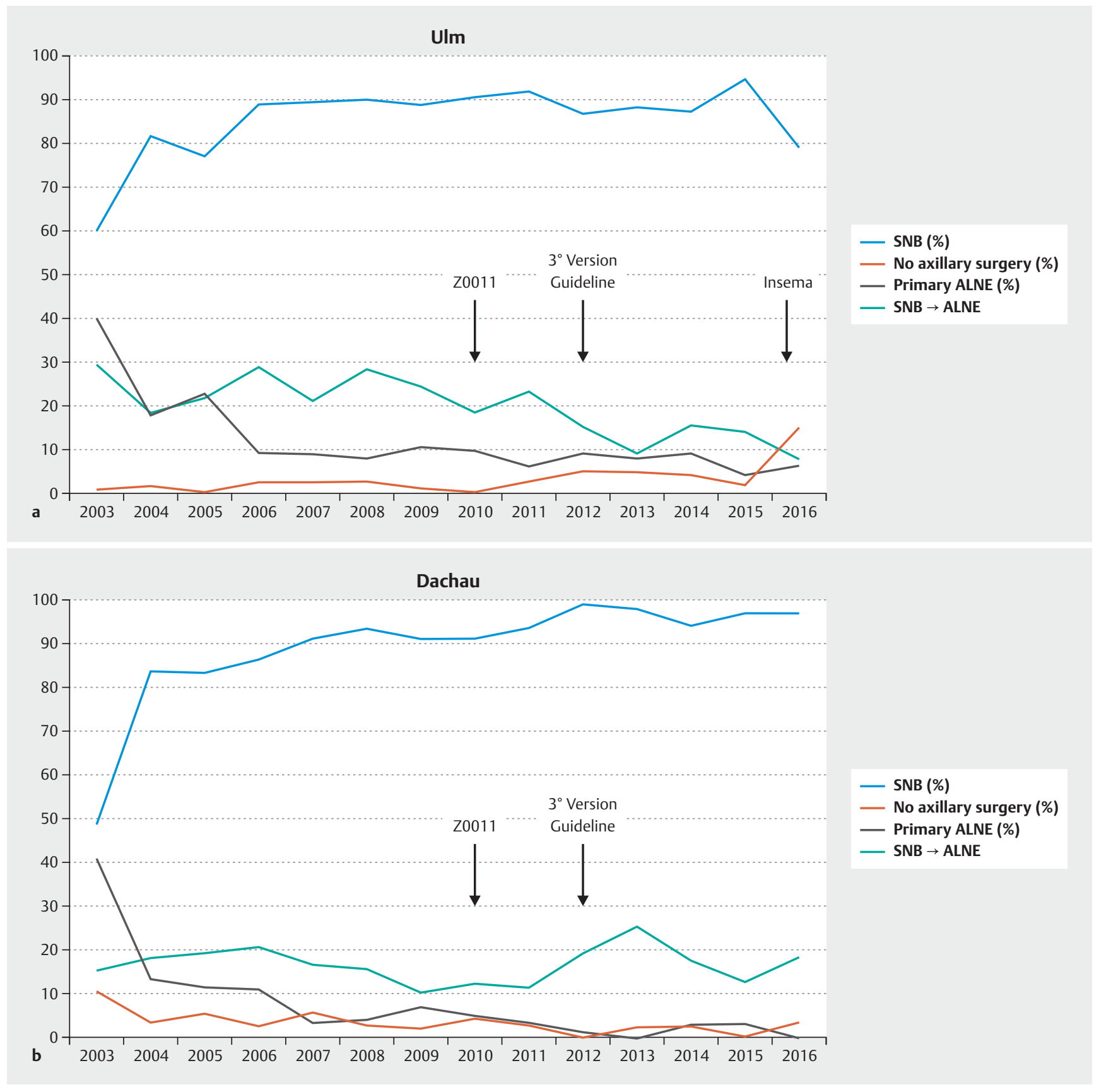

- Fig. 1 a Rates of lymph-node intervention (\%) over the years (2003-2016) at the BCC of the University Hospital Ulm shown for sentinel-node biopsy (SNB), primary axillary lymph node dissection (primary ALNE), secondary ALNE (conversion of SNB to ALNE) and no axillary surgery. b Rate of lymph-node intervention over the years (2003-2016) at the BCC of the Amper Hospital Dachau shown for sentinel-node biopsy (SNB), axillary lymph node dissection (ALNE), secondary ALNE (conversion of SNB to ALNE) and no lymph node surgery.

\section{Discussion}

Implementation of new clinical techniques and guideline recommendations is essential for improved patients' treatment and outcome, but often needs time for establishing [17]. Through scientific work and research activities, actual data might come earlier into daily routine at university hospitals. For evaluating this hypothesis, our analysis focused on the changes in clinical practice with publication of new study data and adapted treatment guidelines in two certified breast cancer centers. In addition, we used pathological and surgical parameters like removed LN as indicators for modified surgical performance.

The number of removed LN in SNB showed a lower value in the university center (2.4 LN/SNB) compared to the D-BCC (3.2 LN/ SNB). This might be due to the higher educational focus usually found in a university hospital. Although the absolute number of 

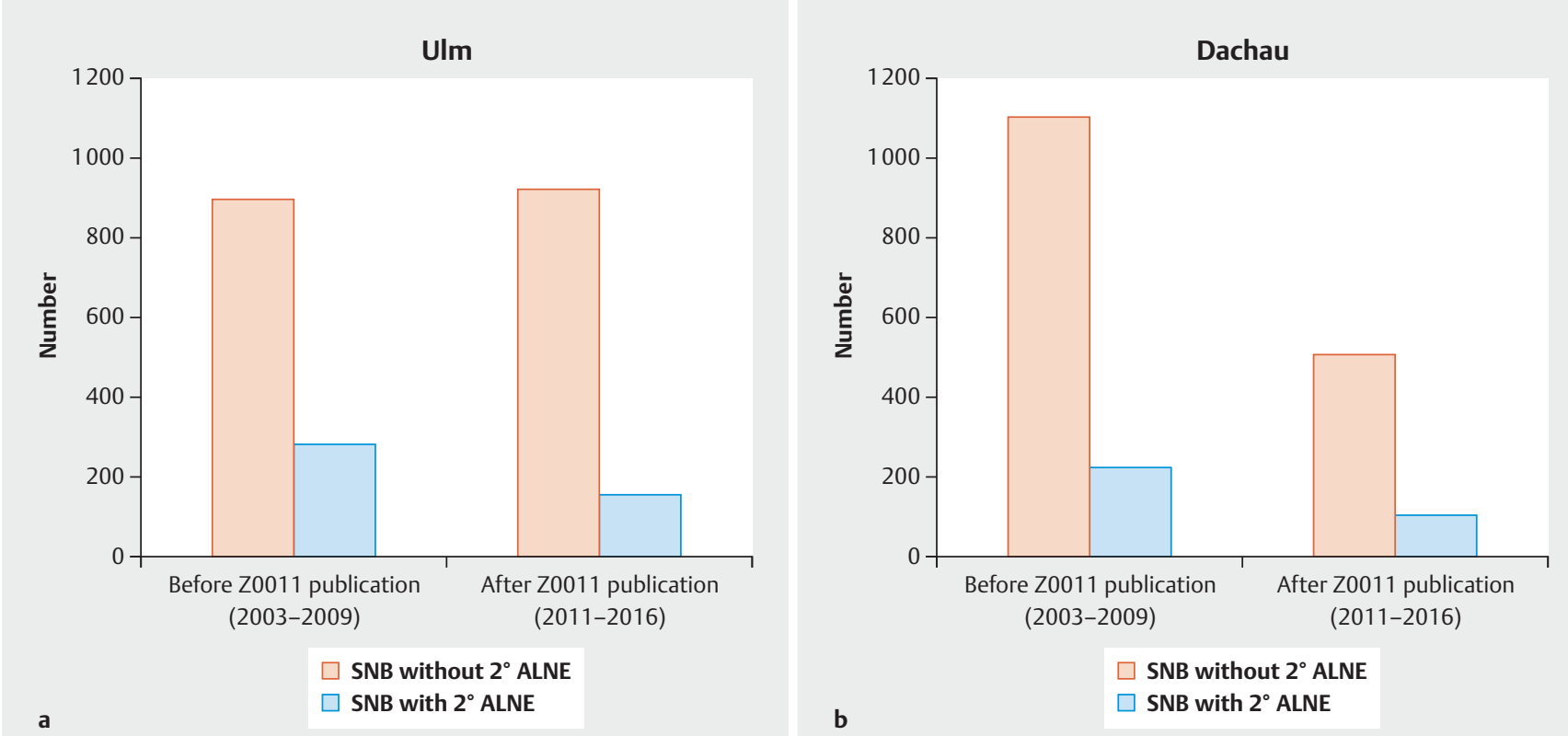

- Fig. 2 a Number of SNBs without (red) or with secondary ALNE (blue) before and after the publication of the Z0011 study (2010) at the BCC Ulm. b Number of SNBs without (red) or with secondary ALNE (blue) before and after the publication of the Z0011 study (2010) at the BCC Dachau.

SNBs vary minimally (Ulm $n=2458$, Dachau $n=2154$ ), this finding might be potentially related to greater experience, better training opportunities, different surgical techniques or alternatively just reflect the surgeons surgical approach. However, the high rate of performed SNB in both BCC $(94.4 \%$ in 2016 in Dachau compared to $94.7 \%$ in 2015 respectively $80.5 \%$ in 2016 in Ulm) suggests adherence to national guideline recommendation for routine use of SNB in clinical node-negative breast cancer, and reveal SNB as a feasible and reliable procedure in clinical routine. Use of SNB increased within the first years and then remained stable with rates of more than $80 \%$ in both BCC. These findings are in line with previous published data, showing an initial SNB rate increase [19] and continuous high values up and above $90 \%[20,21]$. Overall numbers of patients with BCS decreased within the last years in D-BCC ( $\vee$ Table 1) but remained at a stable level in U-BCC. Interestingly, in 2016 a decrease in the rate of SNB from $94.7 \%$ in 2015 to $80.5 \%$ with simultaneous increase of patients not undergoing any surgical axillary intervention was observed at the University Hospital Ulm. With start of the INSEMA trial (Intergroup Sentinel-Mamma) for patients with early, node-negative BC and BCS followed by whole breast irradiation, participating patients at the University Hospital Ulm are randomized to either SNB or non-SNB treatment [22].

For ALNE, an overall trend to less removed LN can be seen in both BCCs represented by the reduction of the total number of removed lymph nodes. In accordance to other published analyses [23], the average of dissected lymph nodes is more than ten lymph nodes with median values of 15.7 removed $L N$ at the U-BCC and 11.5 at the D-BCC. However, current national guideline do not mention the previously requested number of ten or more lymph nodes for ALNE anymore [14]. Over the years, the rate of primary ALNE decreased in both BCCs; the still higher rate of primary ALNE at the university hospital might be due to a higher risk patients' collective in the university setting.

However, most notable is the course of secondary ALNE rates at the BCCs. The observed decrease in conversion rate over the years in Ulm might be related to different reasons. Next to improved preoperative diagnosis with axillary ultrasound and core needle biopsy, leading to a more precise estimation of nodal status, other more general factors such as earlier diagnosis of BC with less $\mathrm{LN}$ involvement due to $\mathrm{BC}$ screening might contribute to this development.

The publication of ACOSOG Z0011 resulted in worldwide practice change and subsequent (inter)national guideline modifications. According to the outcome data of Z0011, in cases of only one or two involved sentinel-lymph nodes, ALNE could be spared for patients undergoing BCS with whole-breast irradiation afterwards. At the U-BCC, a comparison of the conversion rates pre and after Z0011 showed a statistically significant decrease of the rate of performed secondary ALNEs, which seems to be clearly related to the published Z0011 study results. Similar trends were also observed in other countries [24]. This observed decrease of ALNE in patients with positive sentinel node(s) since the publication of the Z0011 trial represents a clinically relevant practice change based on current published research results. For a more precise timed analysis, Tsao et al. used three time periods and also showed a marked decrease in the rate of ALNE after positive SNB following the publication of ACOSOG Z0011 [20]. Overall, following the presentation of the Z0011 study results, remarkable quick changes in clinical routine were observed. However, based on the controversial discussion of Z0011 with its methodical limitations, these rapid adaptions of treatment strategies with omission of 
- Table 1 Numbers and rates (percentage of total number of patients with information on type of surgery) per year for the breast cancer centers Ulm and Dachau.

\begin{tabular}{|c|c|c|c|c|c|c|c|c|c|c|c|c|c|c|}
\hline & 2003 & 2004 & 2005 & 2006 & 2007 & 2008 & 2009 & 2010 & 2011 & 2012 & 2013 & 2014 & 2015 & 2016 \\
\hline \multicolumn{15}{|l|}{ Ulm (U-BCC) } \\
\hline $\begin{array}{l}\text { Median number of } \\
\text { resected LN for SNB }\end{array}$ & 2.8 & 2.6 & 2.5 & 2.3 & 2.5 & 2.5 & 2.4 & 2.4 & 2.9 & 2.3 & 2.0 & 1.7 & 1.8 & 1.8 \\
\hline $\begin{array}{l}\text { Median number } \\
\text { of resected LN for } \\
\text { ALNE }\end{array}$ & 17.3 & 18.4 & 20.3 & 20.0 & 18.2 & 18.8 & 15.9 & 15.2 & 15.5 & 14.2 & 9.1 & 9.3 & 6.0 & 15.4 \\
\hline $\begin{array}{l}\text { Rate of performed } \\
\text { SNB in \% }\end{array}$ & 59.9 & 81.3 & 77.0 & 89.0 & 89.4 & 89.9 & 89.0 & 90.3 & 91.7 & 86.5 & 88.0 & 87.3 & 94.6 & 79.4 \\
\hline $\begin{array}{l}\text { Rate of performed } \\
\text { primary ALNE in \% }\end{array}$ & 39.5 & 17.2 & 22.6 & 8.7 & 8.5 & 7.7 & 10.2 & 9.3 & 5.8 & 8.7 & 7.6 & 8.8 & 3.8 & 6.0 \\
\hline $\begin{array}{l}\text { Rate of no axillary } \\
\text { intervention in \% }\end{array}$ & 0.6 & 1.4 & 0.4 & 2.3 & 2.1 & 2.4 & 0.8 & 0.4 & 2.5 & 4.8 & 4.4 & 3.9 & 1.6 & 14.7 \\
\hline $\begin{array}{l}\text { Rate of secondary } \\
\text { ALNE (SNB } \rightarrow \text { ALNE) } \\
\text { in \% of all SNBs }\end{array}$ & 29.1 & 18.2 & 21.5 & 28.8 & 20.8 & 28.3 & 24.2 & 18.5 & 23.2 & 15.0 & 9.1 & 15.2 & 13.8 & 7.5 \\
\hline $\begin{array}{l}\text { Total number of } \\
\text { patients with com- } \\
\text { plete information } \\
\text { on type of surgery }\end{array}$ & 172 & 209 & 230 & 172 & 188 & 208 & 246 & 227 & 240 & 208 & 225 & 181 & 184 & 184 \\
\hline $\begin{array}{l}\text { Total number of } \\
\text { patients }\end{array}$ & 173 & 209 & 230 & 172 & 188 & 208 & 246 & 227 & 240 & 208 & 225 & 181 & 209 & 195 \\
\hline \multicolumn{15}{|l|}{ Dachau (D-BCC) } \\
\hline $\begin{array}{l}\text { Median number of } \\
\text { resected LN for SNB }\end{array}$ & 4.5 & 3.3 & 3.5 & 3.5 & 2.7 & 2.8 & 2.5 & 2.7 & 3 & 3.1 & 3.3 & 3.2 & 3 & 3.2 \\
\hline $\begin{array}{l}\text { Median number } \\
\text { of resected LN for } \\
\text { ALNE }\end{array}$ & 16.5 & 13.4 & 12.1 & 11.3 & 11.6 & 12.1 & 11.7 & 12.3 & 10.9 & 10.6 & 11.1 & 10.8 & 10 & 11.4 \\
\hline $\begin{array}{l}\text { Rate of performed } \\
\text { SNB in } \%\end{array}$ & 49.0 & 83.5 & 83.2 & 86.4 & 91.3 & 93.3 & 91.2 & 91.1 & 93.4 & 98.9 & 97.9 & 94.4 & 97.1 & 97.1 \\
\hline $\begin{array}{l}\text { Rate of performed } \\
\text { primary ALNE in \% }\end{array}$ & 40.8 & 13.3 & 11.4 & 11.0 & 3.4 & 3.9 & 6.9 & 4.9 & 3.6 & 1.1 & 0.0 & 2.8 & 2.9 & 0.0 \\
\hline $\begin{array}{l}\text { Rate of no axillary } \\
\text { intervention in \% }\end{array}$ & 10.2 & 3.2 & 5.5 & 2.5 & 5.3 & 2.8 & 1.8 & 4.1 & 3.0 & 0.0 & 2.1 & 2.8 & 0.0 & 2.9 \\
\hline $\begin{array}{l}\text { Rate of secondary } \\
\text { ALNE (SNB } \rightarrow \text { ALNE) } \\
\text { in \% of all SNBs }\end{array}$ & 15.8 & 18.4 & 19.1 & 20.6 & 16.9 & 16.0 & 10.5 & 12.4 & 11.5 & 19.3 & 25.5 & 17.7 & 12.9 & 17.9 \\
\hline $\begin{array}{l}\text { Total number of } \\
\text { patients with com- } \\
\text { plete information } \\
\text { on type of surgery }\end{array}$ & 206 & 248 & 220 & 236 & 207 & 254 & 219 & 247 & 167 & 89 & 96 & 108 & 104 & 69 \\
\hline $\begin{array}{l}\text { Total number of } \\
\text { patients }\end{array}$ & 210 & 250 & 226 & 242 & 212 & 262 & 222 & 253 & 171 & 89 & 99 & 112 & 108 & 71 \\
\hline
\end{tabular}

secondary ALNE are also controversially discussed. The benefit of Z0011 is clearly the reduction of potentially unnecessary surgical radicalism with sparing of subsequent morbidity. However, there are also negative aspects of reduced rates of ALNE that need to be mentioned, as accurate knowledge of nodal status is important for appropriate assessment of patients' recurrence risk. Some patients in the axillary dissection group of the ACOSOG Z0011 trial had more than 4 involved lymph nodes despite initial cNO status. In these patients a more intensive systemic and loco-regional ad- juvant treatment might be missed by omission of secondary axillary dissection even though tumor biology is still the leading parameter guiding adjuvant treatment decisions.

In contrast to the university hospital, no significant change in conversation rate was observed in the D-BCC. For secondary ALNE the rates over time were stable, potentially undermining the hypothesis of earlier practice change in University hospitals compared to non-university clinical departments. However, the findings for the municipal hospital might be biased by different fac- 


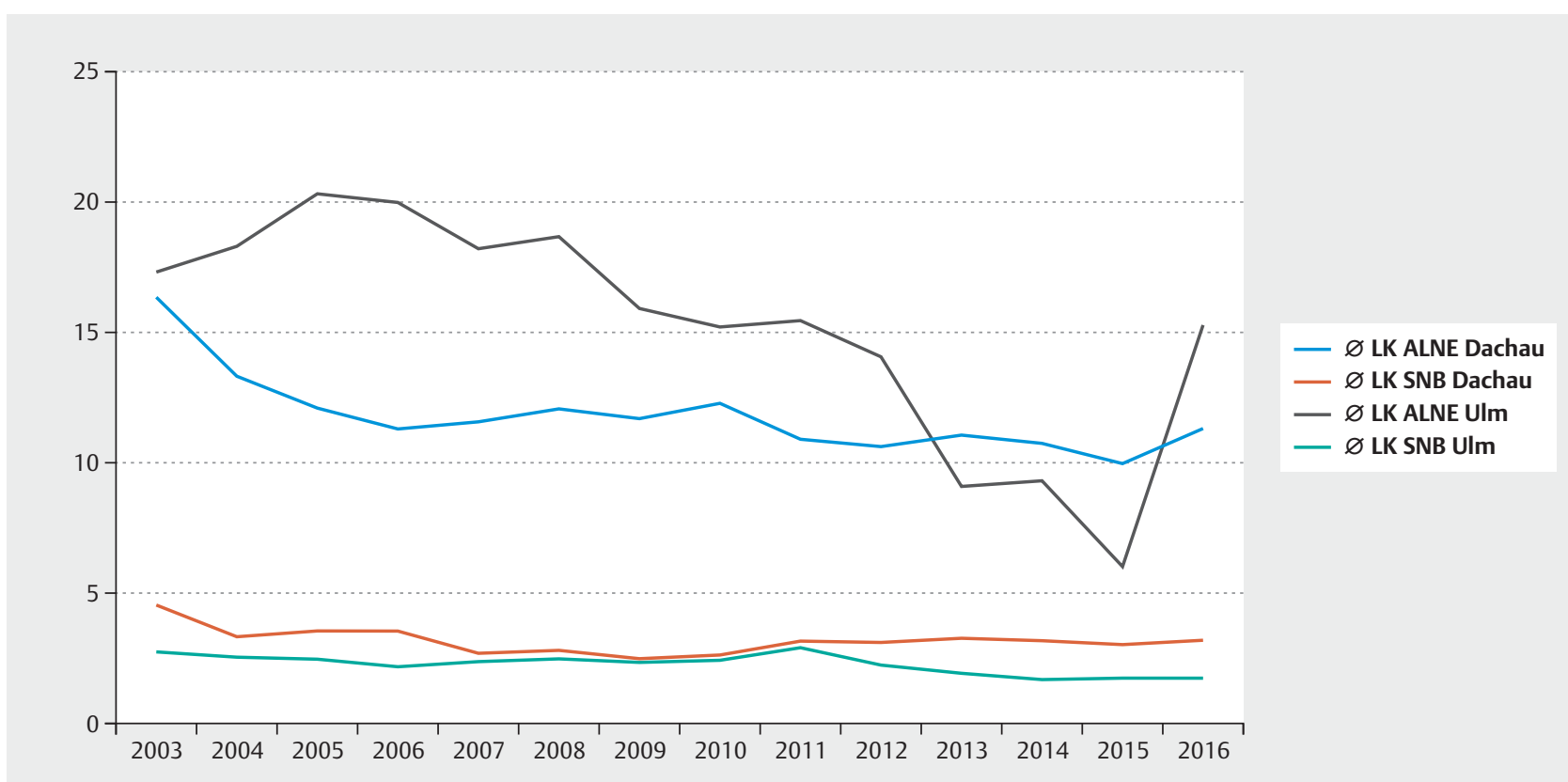

- Fig. 3 Median number of removed lymph nodes for SNB and ALNE over the years (2003-2016) at the BCC of the University Hospital Ulm and the Amper Hospital Dachau.

tors. For example, less precise preoperative LN diagnostic can subsequently result in higher rates of secondary ALNE. In addition, breast surgeons in Dachau could also be more skeptical with regard to the Z0011 results given the already mentioned limitations, and might therefore await further confirmation by additional data. Alternatively, community surgeons might be willing to change clinical practice only if there are higher grades of recommendation in national GL. Awaiting the results of conversion rate in Dachau within the next years might give further explanation and could reveal a delayed practice change in axillary surgery in a municipal hospital. While appliance of Z0011 was only offered as an option in the previous guideline, the recent version - published in 2017 - gives a strong recommendation for axillary treatment according to Z0011 and might now be more consequently implemented at the non-university BCC Dachau.

Limitations of our study come from the retrospective character with information based on the annual status reports mandatory for every BCC. Another weakness of our work are the missing information on histopathological SNB results in that analysis. No specific information was available on positive or negative SNB status and the surgical consequences. Also no specific data for micro- or macrometastases are provided. In order to become a certified BCC the medical quality is regularly checked with internal and external audits. This also includes the adherence to national treatment guidelines. Therefore, it can be assumed that patients treated at a certified BCC undergo surgery according to national guidelines. Consequently, SNB is only performed in patients with clinical node-negative axilla and conversion to $2^{\circ}$ ALNE is restricted to patients with axillary macrometastases. However, due to that missing information, no specific identification of patients fulfilling the Z0011 criteria is possible and thereby, only general trends in axillary surgery can be reported. Due to the anonymization of data, no additional information e.g. for identifying defined subgroups can be acquired by retrieving information from patient files. Also the provided original data cannot be cross checked for plausibility and validity. Still this analysis provides systemic information on data of more than 5400 breast cancer patients treated within the last 14 years with BCS at two certified German breast centers. The findings systematically show a surgical trend over time in both BCCs towards less radical interventions, representing the changing treatment landscape for axillary surgical approach. In addition, our results demonstrate the differences between a community and a university hospital in terms of study participation and implementation of latest study results.

\section{Conclusion}

Our data based on the annual BCC statistics showed that guideline recommendation for surgical treatment of newly diagnosed breast cancer patients are continuously implemented into clinical routine and effects can be seen over time. SNB has been clearly established with increasing precision and ALNE is performed less radical than in the decade before. Performance of secondary ALNE in patients with BCS and prior SNB changed following the publication of ACOSOG Z0011 at the university hospital with a reduction after study presentation. The results also show that treatment recommendations of the certified community hospital are based on national guidelines which are incorporated timely. At least for the management of axillary surgery, trial participation and implementation of new study data even prior to national guidelines recommendations seem to happen earlier in the university hospital setting. 


\section{Conflict of Interest}

The authors (AdG, WJ, JH, NdG etc.) received honoraria and research grants by several industrial companies, but do not have to declare specific conflicts of interest due to economic or personal ties related to this manuscript.

\section{References}

[1] Giuliano AE, Haigh PI, Brennan MB et al. Prospective Observational Study of Sentinel Lymphadenectomy Without Further Axillary Dissection in Patients With Sentinel Node-Negative Breast Cancer. J Clin Oncol 2000; 18: 2553-2559. doi:10.1200/JCO.2000.18.13.2553

[2] Bergkvist L, de Boniface J, Jönsson Phyphen;E et al. Axillary recurrence rate after negative sentinel node biopsy in breast cancer: three-year follow-up of the Swedish Multicenter Cohort Study. Ann Surg 2008; 247: 150-156. doi:10.1097/SLA.0b013e318153ff40

[3] Veronesi U, Paganelli G, Viale G et al. A Randomized Comparison of Sentinel-Node Biopsy with Routine Axillary Dissection in Breast Cancer. N Engl J Med 2003; 349: 546-553. doi:10.1056/NEJMoa012782

[4] Kuehn T, Vogl F, Helms $G$ et al. Sentinel-node biopsy for axillary staging in breast cancer: results from a large prospective German multi-institutional trial. Eur J Surg Oncol 2004; 30: 252-259. doi:10.1016/j.ejso.2003.11.016

[5] Fleissig A, Fallowfield L], Langridge $\mathrm{Cl}$ et al. Post-operative arm morbidity and quality of life. Results of the ALMANAC randomised trial comparing sentinel node biopsy with standard axillary treatment in the management of patients with early breast cancer. Breast Cancer Res Treat 2006; 95: 279-293. doi:10.1007/s10549-005-9025-7

[6] Giuliano AE, McCall L, Beitsch P et al. Locoregional recurrence after sentinel lymph node dissection with or without axillary dissection in patients with sentinel lymph node metastases. Ann Surg 2010; 252: 426432; discussion 432-433. doi:10.1097/SLA.0b013e3181f08f32

[7] Huang TW, Kuo KN, Chen KH et al. Recommendation for axillary lymph node dissection in women with early breast cancer and sentinel node metastasis: A systematic review and meta-analysis of randomized controlled trials using the GRADE system. Int J Surg 2016; 34: 73-80. doi:10.1016/j.ijsu.2016.08.022

[8] Soares EWS, Nagai HM, Bredt LC et al. Morbidity after conventional dissection of axillary lymph nodes in breast cancer patients. World J Surg Oncol 2014; 12: 67. doi:10.1186/1477-7819-12-67

[9] Ebner F, Wöckel A, Janni W et al. Personalized axillary dissection: the number of excised lymph nodes of nodal-positive breast cancer patients has no significant impact on relapse-free and overall survival. J Cancer Res Clin Oncol 2017; 143: 1823-1831. doi:10.1007/s00432-017-2425-3

[10] Morrow M, Harris JR, Schnitt SJ. Local control following breast-conserving surgery for invasive cancer: results of clinical trials. J Natl Cancer Inst 1995; 87: 1669-1673

[11] Houssami N, Macaskill P, Marinovich ML et al. Meta-analysis of the impact of surgical margins on local recurrence in women with early-stage invasive breast cancer treated with breast-conserving therapy. Eur J Cancer 2010; 46: 3219-3232. doi:10.1016/j.ejca.2010.07.043
[12] Moran MS, Schnitt S], Giuliano AE et al. Society of Surgical OncologyAmerican Society for Radiation Oncology Consensus Guideline on Margins for Breast-Conserving Surgery With Whole-Breast Irradiation in Stages I and II Invasive Breast Cancer. J Clin Oncol 2014; 32: 15071515. doi:10.1200/JCO.2013.53.3935

[13] Morrow M, Abrahamse P, Hofer TP et al. Trends in Reoperation After Initial Lumpectomy for Breast Cancer. JAMA Oncol 2017; 3: 1352. doi:10.1001/jamaoncol.2017.0774

[14] Leitlinienprogramm Onkologie (Deutsche Krebsgesellschaft, Deutsche Krebshilfe, AWMF). S3-Leitlinie Früherkennung, Diagnose, Therapie und Nachsorge des Mammakarzinoms, Version 4.1, 2018, AWMF Registernummer: 032-045OL. Online: http://www.leitlinienprogrammonkologie.de/leitlinien/mammakarzinom/; last access: 07.09.2018

[15] Liedtke C, Jackisch C, Thill M et al. AGO Recommendations for the Diagnosis and Treatment of Patients with Early Breast Cancer: Update 2018. Breast Care 2018; 13: 196-208. doi:10.1159/000489329

[16] Untch M, Huober J, Jackisch C et al. Initial Treatment of Patients with Primary Breast Cancer: Evidence, Controversies, Consensus: Spectrum of Opinion of German Specialists at the 15th International St. Gallen Breast Cancer Conference (Vienna 2017). Geburtsh Frauenheilk 2017; 77: $633-$ 644. doi:10.1055/s-0043-111601

[17] Schnoor M, Schäfer T, Welte T. Leitlinien: Aktive Implementierung zeigt Wirkung. Dtsch Arztebl 2010; 107: A-541/B-472/C-646.

[18] Beckmann MW, Schlieter H, Richter P et al. Considerations on the Improved Integration of Medical Guidelines into Routine Clinical Practice a Review and Concept Proposal. Geburtsh Frauenheilk 2016; 76: 369376. doi:10.1055/s-0042-102056

[19] Schrodi S, Niedostatek A, Werner $C$ et al. Is primary surgery of breast cancer patients consistent with German guidelines? Twelve-year trend of population-based clinical cancer registry data. Eur J Cancer Care (Engl) 2015; 24: 242-252. doi:10.1111/ecc.12194

[20] Tsao MW, Cornacchi SD, Hodgson N et al. A Population-Based Study of the Effects of a Regional Guideline for Completion Axillary Lymph Node Dissection on Axillary Surgery in Patients with Breast Cancer. Ann Surg Oncol 2016; 23: 3354-3364. doi:10.1245/s10434-016-5310-4

[21] Mann JM, Wu X, Christos P et al. The State of Surgical Axillary Management and Adjuvant Radiotherapy for Early-stage Invasive Breast Cancer in the Modern Era. Clin Breast Cancer 2018; 18: e477-e493. doi:10.1016/j.clbc.2017.09.001

[22] Reimer T, Stachs A, Nekljudova V et al. Restricted Axillary Staging in Clinically and Sonographically Node-Negative Early Invasive Breast Cancer (c/iT1-2) in the Context of Breast Conserving Therapy: First Results Following Commencement of the Intergroup-Sentinel-Mamma (INSEMA) Trial. Geburtsh Frauenheilk 2017; 77: 149-157. doi:10.1055/s-0042122853

[23] Olaya W, Wong J, Wong J et al. When is a Lymph Node Dissection a Lymph Node Dissection? The Number of Lymph Nodes Resected in Sentinel and Axillary Lymph Node Dissections. Ann Surg Oncol 2013; 20: 627-632. doi:10.1245/s10434-012-2642-6

[24] Joyce DP, Lowery AJ, McGrath-Soo LB et al. Management of the axilla: has Z0011 had an impact? Irish J Med Sci 2016; 185: 145-149. doi:10.1007| s11845-015-1246-0 